\title{
Article \\ Statistically Correlating Laser-Induced Damage Performance with Photothermal Absorption for Fused Silica Optics in a High-Power Laser System
}

\author{
Zhaohua Shi $\mathbb{D}^{\text {, }}$ Laixi Sun *, Ting Shao, Hongjie Liu, Jin Huang, Xin Ye, Fengrui Wang, Liming Yang \\ and Wanguo Zheng
}

Citation: Shi, Z.; Sun, L.; Shao, T.; Liu, H.; Huang, J.; Ye, X.; Wang, F.; Yang, L.; Zheng, W. Statistically Correlating Laser-Induced Damage Performance with Photothermal Absorption for Fused Silica Optics in a High-Power Laser System. Photonics 2022, 9, 137. https://doi.org/10.3390/ photonics 9030137

Received: 8 January 2022

Accepted: 23 February 2022

Published: 26 February 2022

Publisher's Note: MDPI stays neutral with regard to jurisdictional claims in published maps and institutional affiliations.

Copyright: (C) 2022 by the authors. Licensee MDPI, Basel, Switzerland. This article is an open access article distributed under the terms and conditions of the Creative Commons Attribution (CC BY) license (https:// creativecommons.org/licenses/by/ $4.0 /)$.

\author{
Laser Fusion Research Center, China Academy of Engineering Physics, Mianyang 621900, China; \\ shizhaohuacaep@163.com (Z.S.); shaotingcaep@163.com (T.S.); liuhongiiecaep@163.com (H.L.); \\ jinhuangcaep@163.com (J.H.); xinyecaep@163.com (X.Y.); wangfengruicaep@163.com (F.W.); \\ yanglcaep@163.com (L.Y.); zhengwanguocaep@163.com (W.Z.) \\ * Correspondence: sunlaixi@126.com
}

\begin{abstract}
Photothermal weak absorption is useful for the diagnosis of absorbing defects on the surface of fused silica optics in high-power lasers. However, how they relate to the laser-induced damage performance remains unclear, especially for a fused silica surface that has been post-treated with different processes (e.g., dynamic chemical etching or magnetorheological finishing). Here, we present a correlation study on the surface defect absorption level and laser-induced damage performance of fused silica optics post-treated with different processes using the photothermal common-path interferometer method. Statistical distribution of the absorbing defects at various absorption levels is obtained. The relationship between the defect density and the laser damage performance was analyzed. We show that the surface absorbing defects of fused silica can be affected by the post-treatment type and material removal amount. Furthermore, we show that the density of the defects with the absorption over 2 ppm is strongly correlated with the damage initiation threshold and damage density. Especially, for high-density defects at this absorption level, the damage density of fused silica optics can be well-predicted. In the low-density range, the density of this kind of defect can reflect the zero-probability damage threshold well. The study exhibits the potential of this methodology to non-destructively detect the key absorbing defects on fused silica surfaces as well as evaluate and optimize the post-treatment level of fused silica optics for high-power laser applications.
\end{abstract}

Keywords: fused silica; surface absorption; laser-induced damage; absorbing defects; non-destructive evaluation

\section{Introduction}

As an important optical material with excellent properties, fused silica has been widely used in inertial confinement fusion (ICF), such as the National Ignition Facility in the United States [1], the Laser MegaJoule in France [2], and the SG series laser facility in China [3]. As a continuous requirement of the laser output energy, the fact that ultraviolet (UV) laser can easily damage the optical surface of fused silica has caused increasing concern. Although significant progress in surface finishing ability for fused silica optical components has been made in recent years, the surface laser-induced damage threshold (LIDT) of the optics is still far below its bulk damage threshold [4]. For the current operational UV laser fluence of the laser systems, polishing-produced absorbing contaminants (e.g., Ce, Zr, and Fe impurities) and subsurface damage (SSD, typically referring to scratches, micro-cracks, and embedded impurities) are two main kinds of damage precursors responsible for igniting the surface damage of fused silica [5-8]. To improve the damage resistance of fused silica optics, tremendous efforts have been devoted to developing advanced post-treatment techniques, such as magnetorheological finishing (MRF) and HF-based wet etching [9-12]. 
For decades, laser-induced damage testing has been used as a practicable method for evaluating the surface damage resistance of polished fused silica optics $[13,14]$. However, the damage testing is destructive, making the tested optics lose their functions. The surface laser damage process of fused silica can schematically take place as follows. Firstly, defects absorb the incident laser energy and thus lead to the creation of a surface plasma by ionization. Then, the plasma continues to absorb the laser energy, and a strong laser-material coupling effectively generates high temperature and high pressure locally. Finally, the host material responds to the localized energy deposition forming a damage site $[15,16]$. Absorption, which is a common characteristic parameter of various defects on the fused silica surface, can be used as a candidate for the evaluation of laser-induced damage behavior since it is a key step in the stage of laser damage initiation and subsequent growing.

Photothermal and photoacoustic spectroscopies are unique for measuring the weak absorption property of low-loss optical materials [17]. Based on these methodologies, different detecting techniques have been developed for decades, including laser calorimetry (LC), photoacoustic spectroscopy (PAS), photothermal deflection spectroscopy (PDS), and photo-thermal common-path interferometry (PCI) [18]. LC directly measures light-induced temperature change with a thermal detector attached to the tested sample. It has become an ISO standard method [19] to detect the weak absorption coefficient of optical materials. However, this method is greatly inefficient and needs mechanical contact with the sample [20]. PAS can detect the acoustic waves caused by the thermal expansion in the material, which generates from local heating due to laser absorption. A key advantage of PAS measurement is the ability to obtain absorption coefficients across a broad spectrum using an optical parametric oscillator pumped by pulsed lasers as a tunable pump-light source. However, PAS measurement is very sensitive to acoustical noise and also needs direct contact with the sample [20]. PDS and PCI are two non-contact methods for measuring the weak absorption of optical materials according to the thermal lensing effect [21]. Compared with PCI, PDS requires higher pump power and has lower sensitivity [20]. During PCI measurement, a pump laser beam with relatively high power and a small waist is chopped and then focused on the tested location, leading to a tiny change of refractive index resulting from local heating and thermal expansion. In this case, the inner part of the probe laser beam will be disturbed, forming interference with the undisturbed outer part. The interference signal is then detected by a photoelectric detector and is processed by a lock-in amplifier. Since the absorption is measured only in the cross-region of the two beams, PCI can distinguish between bulk absorption and surface absorption of fused silica $[16,17]$. Moreover, PCI can adopt two-dimensional scanning to realize effective statistics on absorbing defects on the material surface, which is difficult to achieve by using other defects detection techniques.

In recent years, photothermal spectroscopy is demonstrated to be a useful technique for the non-destructive characterization of fused silica optical components in high-power laser systems [22,23]. For example, Ju et al. demonstrated the laser damage degree on fused silica surface can be indicated through combining photothermal spectroscopy and optical microscope [24]. Zhong et al. utilized photothermal spectroscopy to characterize nanoscale damage precursors on plasma-etched fused silica surfaces $[25,26]$. Despite these great efforts, the correlation between defects at various absorption levels and damage performance on fused silica surfaces is still not fully clarified due to the complexity of these absorbing defects. More importantly, for polished fused silica optics that have undergone HF-based etching with different removal amounts, the distribution characters of the absorbing defects at various absorption levels are different. Among these absorbing defects on the treated fused silica surface, which absorption level dominates the damage resistance is also not revealed yet.

In this work, different post-treatment processes are used to obtain different fused silica optical surfaces. The weak absorption level of the defects on the treated, fused silica surfaces was detected through photothermal spectroscopy based on PCI. Laser-induced damage performance (damage probability and density) of the optics were evaluated. By 
establishing the correlation statistically between weak absorption and damage performance, this methodology can be used as a tool to evaluate and optimize the polishing process, as well as the post-processing level of fused silica optics.

\section{Materials and Methods}

\subsection{Samples Preparation}

Six square high-pure fused silica samples (Corning 7980, $50 \mathrm{~mm} \times 50 \mathrm{~mm} \times 5 \mathrm{~mm}$ ) were manufactured using conventional polishing processes with $\mathrm{CeO}_{2}$ as the abrasive. Sample A1 was an originally polished one without any post-treatment. Five samples (samples A2, A3, B, C, and D) were polished with different post-treatment processes to offer different surface characters of absorbing defects. Two samples (samples A2, and A3) were post-treated with HF-based dynamic chemical etching (DCE, which will be described in detail in the following subsection). The other three samples (samples B, C, and D) were post-treated with MRF. A white light interferometer was employed to measure the surface roughness (RMS, root mean square) of the samples. The post-treatment methods and the surface roughness of the samples are shown in Table 1 . The roughness of the original sample surface was $0.81 \mathrm{~nm}$. After the sample was post-treated with HF-based etching with the removal amount of $1 \mu \mathrm{m}$, the surface roughness decreased to $0.68 \mathrm{~nm}$. The slight decrease in surface roughness of the sample was attributed to the removal of the redeposition layer of polished fused silica. However, when the etching depth increased to $10 \mu \mathrm{m}$, the roughness increased to $1.15 \mathrm{~nm}$. The surface quality degradation of deep-etched fused silica stemmed from the isotropic effect of the wet etching, which could leave the etching trace of SSD. The surface quality of the samples post-treated with MRF showed a similar level (about 1.1-1.2 nm), indicating that MRF treatment would degrade the surface quality of fused silica but the removal amount of MRF had a weak impact on the surface roughness.

Table 1. Sample preparation methods and roughness on the sample surfaces.

\begin{tabular}{ccc}
\hline Sample & Post-Treatment & Roughness (nm) \\
\hline A1 & Original & 0.81 \\
A2 & DCE 1 $\mu \mathrm{m}$ & 0.68 \\
A3 & DCE 10 $\mu \mathrm{m}$ & 1.15 \\
B & MRF 1 $\mu \mathrm{m}$ & 1.19 \\
C & MRF 2 $\mu \mathrm{m}$ & 1.11 \\
D & MRF 5 $\mu \mathrm{m}$ & 1.17 \\
\hline
\end{tabular}

\subsection{Post-Treatments}

DCE treatment was carried out under a seven-frequency ultrasonic transducer (Blackstone multiSONIK ${ }^{\mathrm{TM}}, 40 \mathrm{kHz}, 80 \mathrm{kHz}, 120 \mathrm{kHz}, 140 \mathrm{kHz}, 170 \mathrm{kHz}, 220 \mathrm{kHz}$, and $270 \mathrm{kHz}$ ). Before HF-based DCE, all samples were submerged in Micro90 solution for $80 \mathrm{~min}$ and rinsed with deionized water for common cleaning. During the DCE process, the samples were submerged in an HF-acid etchant consisting of $49 \mathrm{wt} . \% \mathrm{HF}$ and $30 \mathrm{wt} . \% \mathrm{NH}_{4} \mathrm{~F}$ with a volume ratio of 1:4 and followed by the same rinsing procedure. The HF etching rate was $0.1 \mu \mathrm{m} / \mathrm{min}$, which was initially calibrated by surface profilometer. Finally, the treated samples were rinsed using deionized water and allowed to air dry. A detailed description of the etching process can be found in the literature [27]. MRF process was conducted on a KDUPF-700 MRF machine tool (developed by the National University of Defense Technology [12]) with $\mathrm{CeO}_{2}$ as the polishing particles. The size of the particles was about $0.2 \mu \mathrm{m}$. We controlled the removal rate to be about $1.8 \times 10^{7} \mu \mathrm{m}^{3} / \mathrm{min}$ during the MRF treatment. Similarly, the treated samples were also rinsed using deionized water and allowed to air dry.

\subsection{Weak Absorption Measurement}

Figure 1 shows the schematic of the PCI experimental setup used for the weak absorption measurement. A $1 \mathrm{~W}$ quasi-continuous laser $(355 \mathrm{~nm})$ with the beam quality 
factor of $\mathrm{M}^{2}<1.1$ was used as a pump beam. The wavelength linewidth of the laser was about $0.5 \mathrm{~nm}$. A $5 \mathrm{~mW}$ He-Ne laser $(632.8 \mathrm{~nm})$ was used as a probe beam. The detection sensitivity of the system can approach $0.4 \mathrm{ppm}$. Before the measurement, the setup was first calibrated using a commercial metal-coated fused silica at $355 \mathrm{~nm}$. The scanning strategy was executed across the sample surface to obtain two-dimensional absorption distribution $(3 \mathrm{~mm} \times 3 \mathrm{~mm}$ with the detecting step of $50 \mu \mathrm{m})$. In the experiment, three testing regions were randomly chosen on each sample surface to obtain the statistical distribution of absorbing defects.

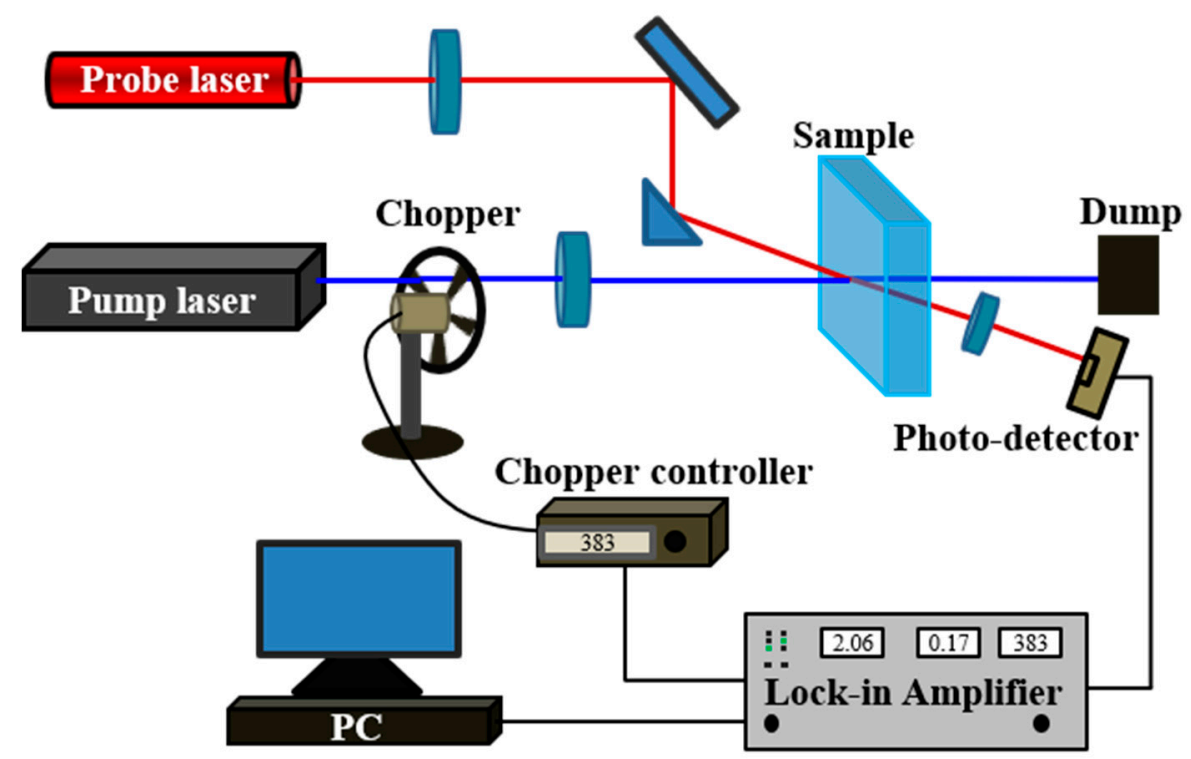

Figure 1. Schematic of the PCI experimental setup for the weak absorption measurement.

\subsection{Laser-Induced Damage Test}

Laser-induced damage performance measurements were performed using a tripled $\mathrm{Nd}$ : YAG system, which was used to provide a pulse laser at $355 \mathrm{~nm}, 9.3 \mathrm{~ns}$ pulse duration (FWHM) with the repetition frequency of $10 \mathrm{~Hz}$. The quality factor $\left(\mathrm{M}^{2}\right)$ of the laser beam was lower than 1.3. The laser pulse energy was adjusted using a computer-controlled waveplate/polarizer. A fused silica pickoff wedge reflected two beams for the detection of pulse energy and beam profile. During the test, the laser beam was focused by a long-focus lens to provide a near flat-top beam with a diameter of $1.4 \mathrm{~mm}\left(1 / \mathrm{e}^{2}\right)$. The area of the focal spot at the back surface (exit surface) of the samples was a little smaller than that at the front surface (input surface) of the samples. The damage was thus readily initiated at the back surface of the samples. The modulation (peak energy/average energy) of the laser beam spot was 1.6 and the wavelength linewidth was $0.001 \mathrm{~nm}$. Online optical microscopy with a spatial resolution of $\sim 2 \mu \mathrm{m}$ was used to real-time monitor the damage initiation. The damage threshold was measured with a 1-on-1 strategy (following ISO 21254). Damage fluence in this paper was rescaled to a 3 ns pulse duration using 1/2 law [28]. Twenty testing sites for each laser fluence were chosen randomly on each sample surface. We used "Raster-Scan" damage test method to obtain the damage density as a function of laser fluence. The sampling area of the damage density test was $10 \mathrm{~cm}^{2}$ for each laser fluence. A detailed description of the testing strategies can be found in the literature [27].

\section{Results}

The 3D absorption mapping of absorbing defects on each sample surface is shown in Figure 2. The mapping can reveal absorption topography, average absorption, peak absorption intensity, and corresponding defect density of the sample surfaces. The results show that there were many discrete absorption peaks on originally polished sample surfaces due to the presence of absorbing impurities and SSD produced during the conventional 
polishing process. After DCE treatment (no matter for $1 \mu \mathrm{m}$ or $10 \mu \mathrm{m}$ etching depth), the density of absorption peaks on the sample surfaces decreased significantly, suggesting that the polishing-introduced absorbing defects can be effectively removed by the etching treatment. It can be noted that the MRF treatment can also influence the density of the surface defects but for the three selected removal amounts $(1 \mu \mathrm{m}, 2 \mu \mathrm{m}$, and $5 \mu \mathrm{m})$ the effect is very different. For the 1- $\mu \mathrm{m}$ MRF sample, the density of the absorbing defects dropped obviously. When increasing the removal amount to $2 \mu \mathrm{m}$, the density of the defects continually decreased. However, with the removal amount of $5 \mu \mathrm{m}$, there were a great many absorbing defects, whose intensity was even higher than that on the originally polished sample surface. The results revealed that $2 \mu \mathrm{m}$ was an optimal removal amount for effectively eliminating the absorbing defects produced by the conventional polishing process and deeper MRF treatment would introduce other absorbing defects.

(a) A1: Original

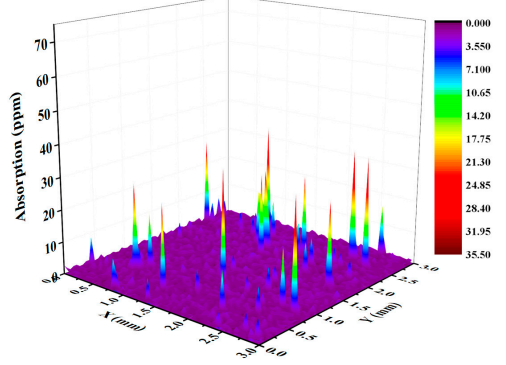

(d) B: MRF $1 \mu \mathrm{m}$

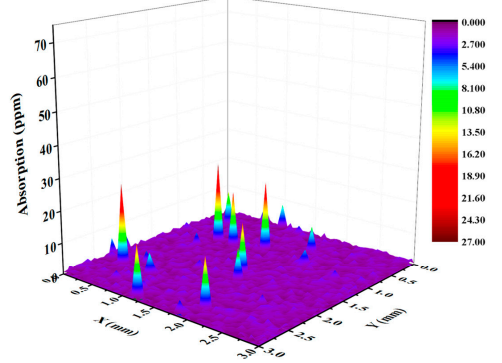

(b) A2: DCE $1 \mu \mathrm{m}$

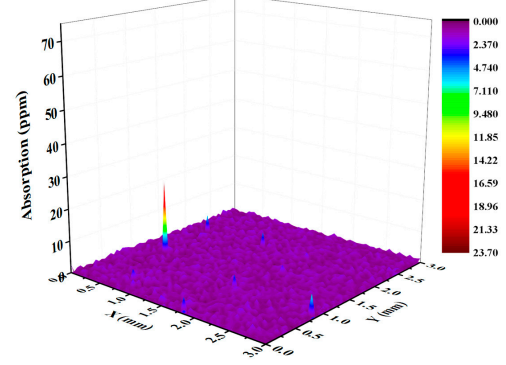

(e) C: MRF $2 \mu \mathrm{m}$

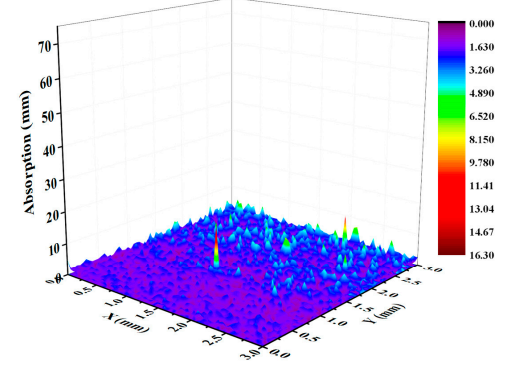

(c) A3: DCE $10 \mu \mathrm{m}$

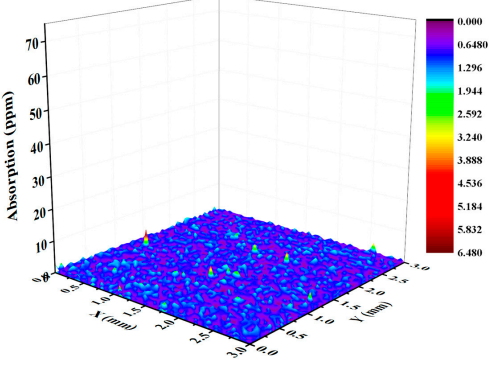

(f) D: MRF $5 \mu \mathrm{m}$

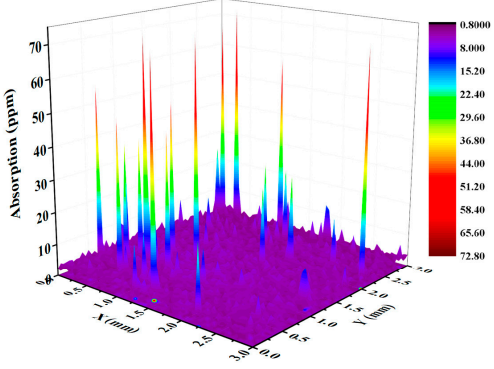

Figure 2. Weak absorption mapping at $355 \mathrm{~nm}$ of sample surfaces. Each scan area size was $3 \mathrm{~mm} \times 3 \mathrm{~mm}$ with the detecting step of $50 \mu \mathrm{m}$. The $X$ and $Y$ axes represent position information, and the $\mathrm{Z}$-axis represents the surface absorption intensity of fused silica optics.

To obtain the density of the absorbing defects at various absorption levels and corresponding average and maximum absorption values on the treated sample surfaces, we conducted mathematical statistics for all the obtained 3D absorption data, as shown in Table 2. It can be noted from the table that the distribution of the absorbing defects was very dependent on the post-treatment process. The average absorption and maximum absorption varied from $0.859 \mathrm{ppm}$ to $5.372 \mathrm{ppm}$ and from $11.1 \mathrm{ppm}$ to $259.0 \mathrm{ppm}$, respectively. The densities of the absorbing defects at various absorption levels on the treated sample surfaces were also different, as shown in Figures 3 and 4. For the samples treated with MRF, as shown in Figure 3, defects at the same absorption level had very different distribution densities. The results showed that the MRF removal amount could influence the density of the absorbing defects on the fused silica surface. However, the HF etching depth had a relatively weak influence on the surface defect density (see the red and blue lines in Figure 4). For the samples treated with $1 \mu \mathrm{m}$ DCE, the average absorption decreased from 1.219 ppm to $0.862 \mathrm{ppm}$, and the maximum absorption was also significantly reduced. When increasing the HF etching depth, the average absorption decreased slightly but the maximum absorption decreased obviously. Comparing the defect densities at various absorption levels of the DCE-treated samples, we can find that the obvious decrease in max- 
imum absorption might attribute to the decrease in density of the defects whose absorption value high than 2 ppm (see Table 2).

Table 2. Photothermal absorption statistic results including characteristic absorption and defect density with different absorption levels.

\begin{tabular}{|c|c|c|c|c|c|c|c|c|c|c|c|}
\hline \multirow{2}{*}{ Sample } & \multirow{2}{*}{$\begin{array}{l}\text { Maximum } \\
(\mathrm{ppm})\end{array}$} & \multirow{2}{*}{$\begin{array}{c}\text { Average } \\
\text { (ppm) }\end{array}$} & \multicolumn{9}{|c|}{ Defect Density $\left(\mathrm{mm}^{-2}\right)$} \\
\hline & & & $>1 \mathrm{ppm}$ & $>1.5 \mathrm{ppm}$ & $>2 \mathrm{ppm}$ & $>3 \mathrm{ppm}$ & $>4 \mathrm{ppm}$ & $>5 \mathrm{ppm}$ & $>7 \mathrm{ppm}$ & $>10 \mathrm{ppm}$ & $>15$ ppm \\
\hline A1 & 41.9 & 1.219 & 191.89 & 55.70 & 17.15 & 8.78 & 6.93 & 5.81 & 4.33 & 3.19 & 2.04 \\
\hline A2 & 27.3 & 0.862 & 134.70 & 30.74 & 3.85 & 1.15 & 0.63 & 0.48 & 0.33 & 0.33 & 0.15 \\
\hline A3 & 11.1 & 0.859 & 136.85 & 26.37 & 3.22 & 0.44 & 0.15 & 0.07 & 0.04 & 0.04 & 0.00 \\
\hline B & 37.7 & 1.673 & 235.33 & 105.48 & 41.70 & 22.30 & 18.96 & 16.78 & 13.89 & 9.89 & 5.48 \\
\hline C & 19.1 & 2.155 & 349.67 & 269.93 & 182.93 & 77.70 & 32.70 & 14.52 & 3.52 & 0.482 & 0.11 \\
\hline $\mathrm{D}$ & 259.0 & 5.372 & 391.44 & 370.33 & 345.74 & 276.56 & 183.22 & 127.70 & 75.19 & 32.89 & 15.96 \\
\hline
\end{tabular}

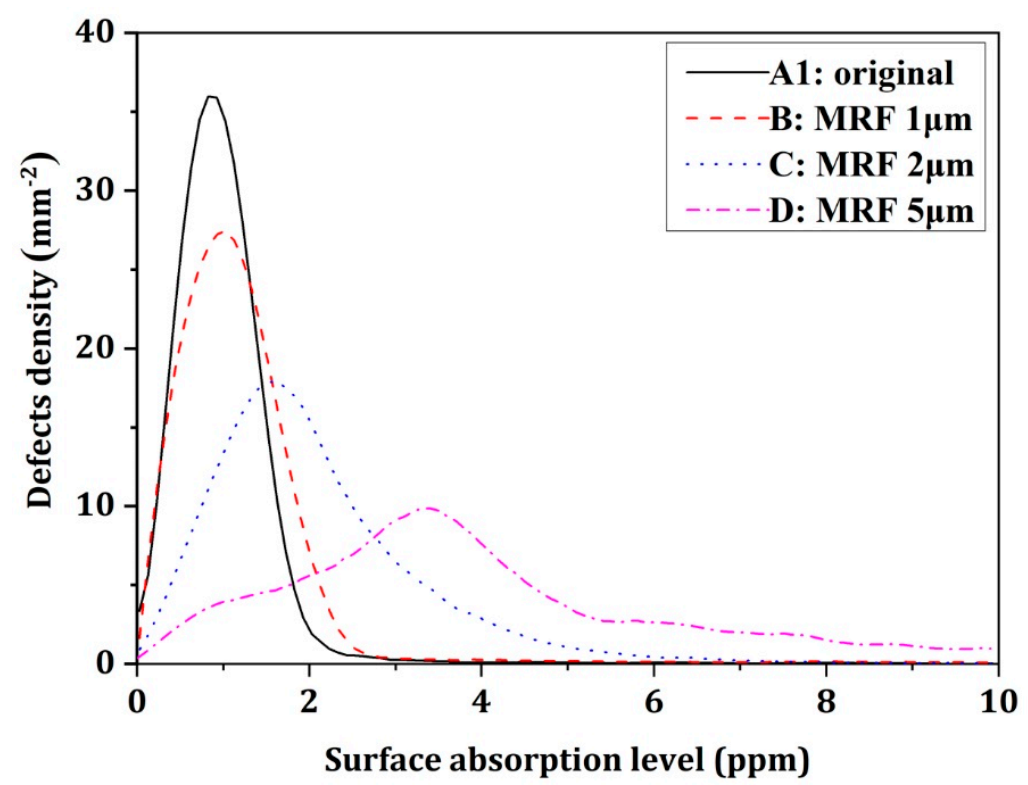

Figure 3. Weak absorption distribution curves of all polished sample surfaces.

Previous studies have evidenced that mechanical polishing can lead to photosensitive impurities and SSD, and the DCE and MRF techniques can reduce these defects. In the experiment, we used the two post-treatment processes to obtain fused silica optical surfaces with different defect distributions, and the LIDT of each sample at $355 \mathrm{~nm}$ laser pulse radiation is shown in Figure 5. Noted that the MRF process had a weak effect on damage thresholds of the fused silica samples. For DCE-treated samples, however, the LIDT increased dramatically. It was noted that the original polished sample A1 had a very low zero-probability damage threshold $\left(7.6 \mathrm{~J} \cdot \mathrm{cm}^{-2}\right)$. Significant improvement can be observed when the fused silica sample was treated with $1-\mu \mathrm{m}$ and $10-\mu \mathrm{m}$ HF-based etching, and the corresponding damage thresholds of zero probability were $12.5 \mathrm{~J} \cdot \mathrm{cm}^{-2}$ and $14.6 \mathrm{~J} \cdot \mathrm{cm}^{-2}$, respectively. The results demonstrated that post-treatment processes have an important effect on the laser damage resistance of fused silica optics. 


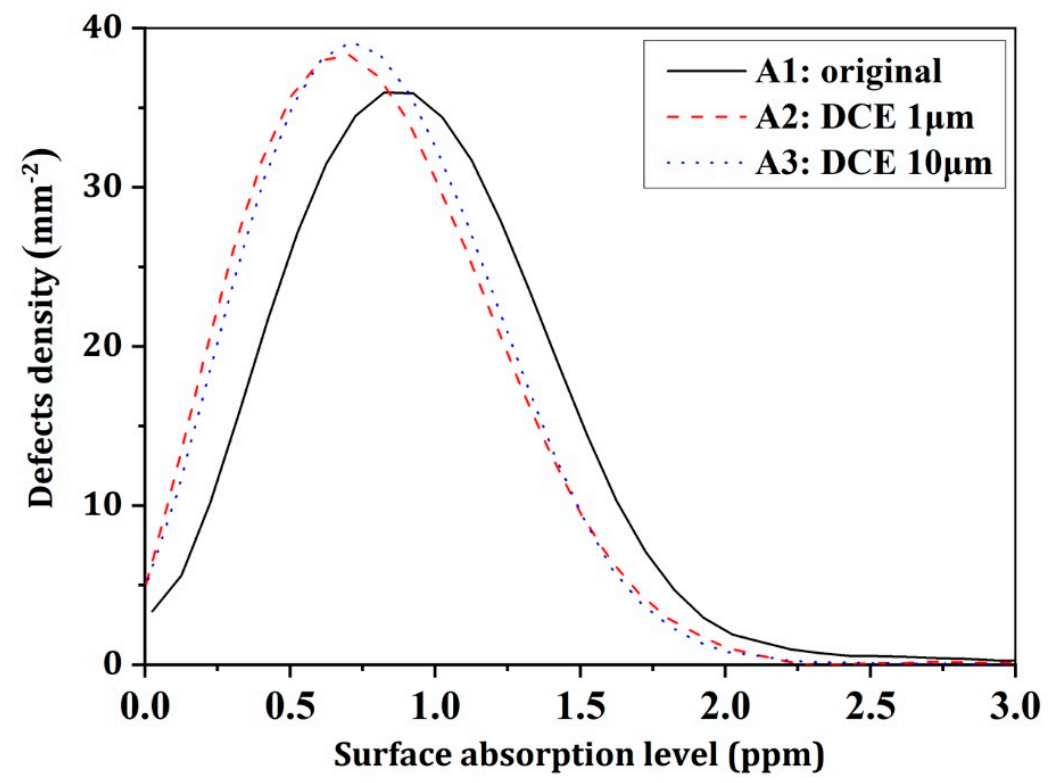

Figure 4. Weak absorption distribution curves of post-treated surfaces.

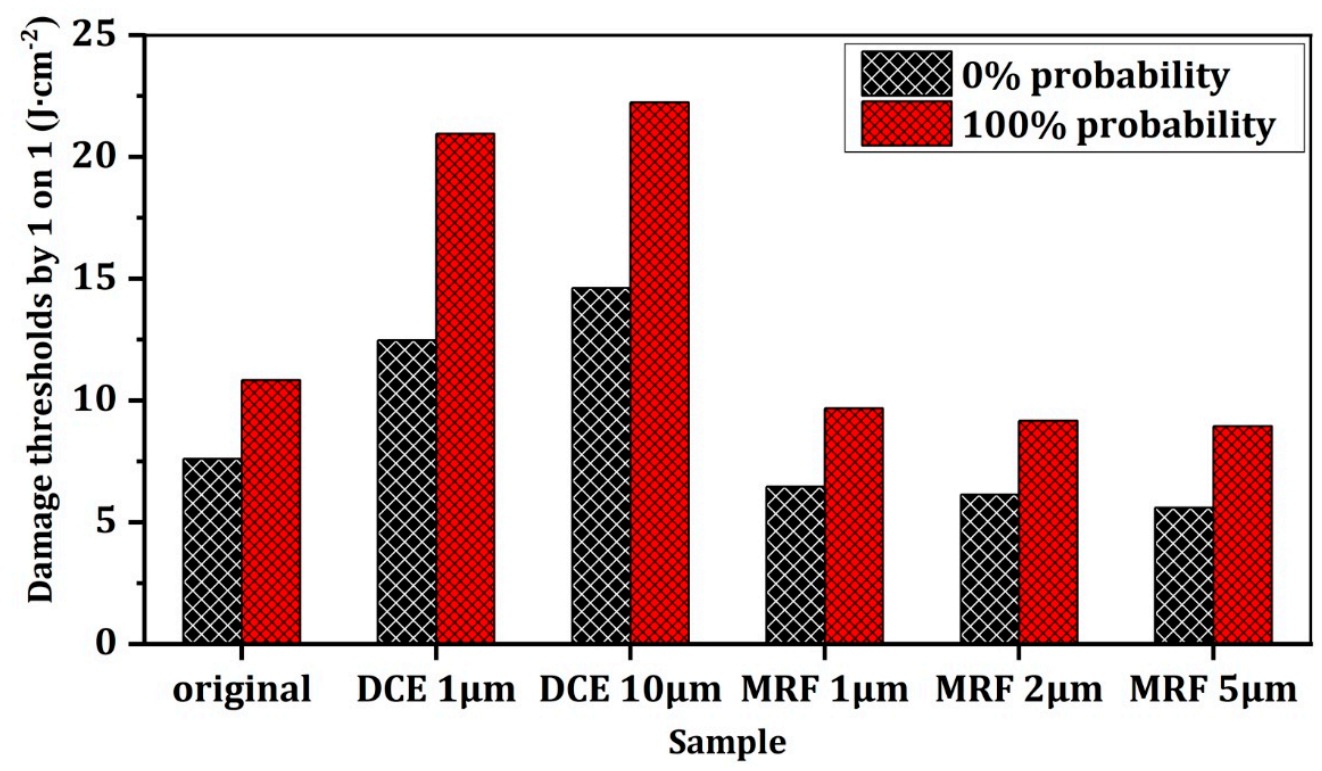

Figure 5. Damage thresholds for all the fused silica samples. Black columns represent the zeroprobability damage thresholds and red columns represent $100 \%$-probability damage thresholds.

We also tested the damage density as a function of laser fluence using the "Raster-Scan" method. As Figure 6 shows, there was an obvious difference in damage density of the MRF-treated samples. At high laser fluence, particularly, the damage density varied by one order of magnitude. The damage densities of DCE-treated samples decreased more than two orders of magnitude compared to the unetched original samples. To distinguish the difference of damage density for the samples treated with different processes, we used $8 \mathrm{~J} \cdot \mathrm{cm}^{-2}$ laser fluence (which is a typical operation fluence for high-power laser facilities) as a reference standard. Table 3 shows the damage densities of the fused silica samples at the laser fluence of $8 \mathrm{~J} \cdot \mathrm{cm}^{-2}$. For DCE-treated samples, the damage density was decreased from $2.0941 \mathrm{~cm}^{-2}$ to $0.0134 \mathrm{~cm}^{-2}$ after $10-\mu \mathrm{m}$ DCE treatment. 


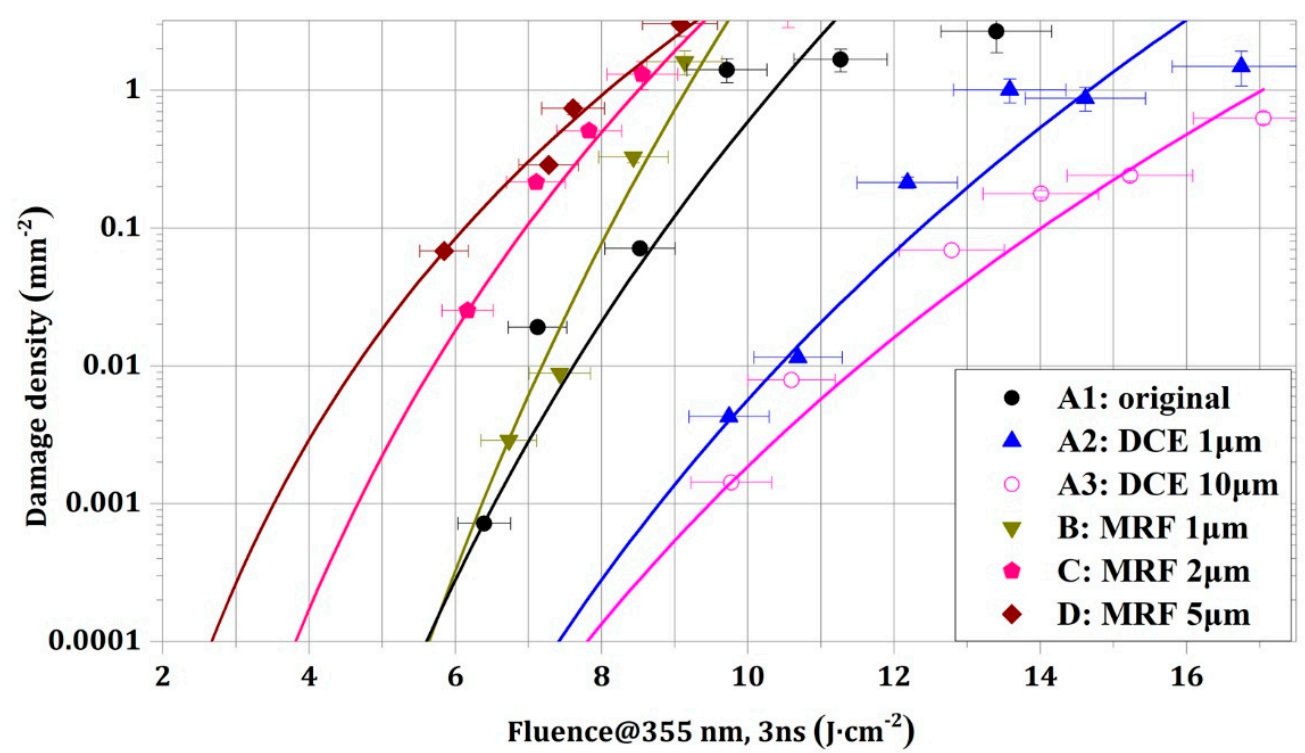

Figure 6. Damage densities versus fluence for all the fused silica samples. Damage fluence was rescaled to 3 ns pulse duration using $1 / 2$ law.

Table 3. Damage density of all fused silica samples at $8 \mathrm{~J} \cdot \mathrm{cm}^{-2}$ fluences.

\begin{tabular}{cc}
\hline Sample & Damage Density $\left(\mathbf{c m}^{-\mathbf{2}}\right)$ \\
\hline A1 (original) & 2.0941 \\
A2 (DCE $1 \mu \mathrm{m})$ & 0.0281 \\
A3 (DCE $10 \mu \mathrm{m})$ & 0.0134 \\
B (MRF $1 \mu \mathrm{m})$ & 7.7597 \\
C (MRF $2 \mu \mathrm{m})$ & 49.8306 \\
D (MRF $5 \mu \mathrm{m})$ & 91.8621 \\
\hline
\end{tabular}

\section{Discussion}

Laser-induced damage of fused silica surface is due to defect-induced absorption of sub-bandgap light. To better understand the effect of surface absorption on damage resistance of the samples treated with different post-treatment processes, the Spearman correlation between surface absorption parameters (average, maximum, and defect density at various absorption levels) and damage performance were analyzed according to the following equation:

$$
r(s)=1-\frac{6 \sum_{i=1}^{n} d_{i}^{2}}{n\left(n^{2}-1\right)},
$$

where $d_{i}$ is the difference between ranks for each $x_{i}, y_{i}$ data pair and $n$ is the number of data pairs. Spearman rank correlation coefficient (Corr.) and significance (Sig.) are the two most commonly used statistical parameters to evaluate the correlation between two variables. When the absolute value of Corr. is 1 , the two variables are completely correlated and when its absolute value is 0 , it reveals that the two variables are completely uncorrelated. A large absolute value of Corr. (e.g., 0.8) indicates a high correlation. The negative sign represents monotonic decreasing while the positive sign represents monotonic increasing. The value of Sig. indicates the credibility of the Spearman correlation results. The Sig. value should be less than 0.05, otherwise, the Spearman correlation is not reliable [29].

The calculated results are shown in Tables 4 and 5. Note that the absorption parameters were negatively correlated with zero-probability damage threshold, and positively correlated with damage density at $8 \mathrm{~J} \cdot \mathrm{cm}^{-2}$. It can be also noted from the tables that the correlation between the damage performance and defect density was very dependent on the absorption level of the detected defects on the sample surfaces. The correlation coefficient (absolute value of Corr.) increased first and then decreased with the increase 
in the defect absorption level. It also can be noted that the correlation coefficient between damage performance (no matter for zero-probability damage threshold or damage density) and defect density reached a maximum when the absorption level of defects is higher than $2 \mathrm{ppm}$. It suggested that the defects at this absorption level were responsible for the laser damage, especially at $8 \mathrm{~J} \cdot \mathrm{cm}^{-2}$ fluences. For the defects with the absorption below $2 \mathrm{ppm}$, it was difficult to reach the damage initiation condition at the given laser fluence. With the absorption level increased, the density of the corresponding defects decreased greatly. In this case, the laser beam spot of the damage testing system had a relatively low probability to capture these low-density defects.

Table 4. Spearman correlations between zero probability damage thresholds and the density of the defects with different absorption levels.

\begin{tabular}{|c|c|c|c|}
\hline & & Spearman Corr. & Sig. \\
\hline \multicolumn{2}{|c|}{ Maximum } & -0.52381 & 0.18272 \\
\hline \multicolumn{2}{|c|}{ Average } & -0.92857 & 0.00086 \\
\hline \multirow{9}{*}{ Absorption level of the defect } & $>1.0 \mathrm{ppm}$ & -0.85714 & 0.00653 \\
\hline & $>1.5 \mathrm{ppm}$ & -0.92857 & 0.00086 \\
\hline & $>2.0 \mathrm{ppm}$ & -0.97619 & 0.00003 \\
\hline & $>3.0 \mathrm{ppm}$ & -0.90476 & 0.00201 \\
\hline & $>4.0 \mathrm{ppm}$ & -0.90476 & 0.00201 \\
\hline & $>5.0 \mathrm{ppm}$ & -0.85714 & 0.00653 \\
\hline & $>7.0 \mathrm{ppm}$ & -0.76190 & 0.02800 \\
\hline & $>10.0 \mathrm{ppm}$ & -0.76190 & 0.02800 \\
\hline & $>15.0 \mathrm{ppm}$ & -0.64286 & 0.08556 \\
\hline
\end{tabular}

Table 5. Spearman correlation between damage densities at $8 \mathrm{~J} \cdot \mathrm{cm}^{-2}$ and density of the defects with different absorption levels.

\begin{tabular}{ccccc}
\hline & & Spearman Corr. & Sig. & \\
\hline & Maximum & & 0.42857 & 0.28940 \\
\hline & Average & & 0.88095 & 0.00385 \\
& & $>1.0 \mathrm{ppm}$ & 0.78571 & 0.02082 \\
Absorption level of the defect & $>1.5 \mathrm{ppm}$ & 0.88095 & 0.00385 \\
& $>2.0 \mathrm{ppm}$ & 0.95238 & 0.00026 \\
& $>3.0 \mathrm{ppm}$ & 0.83333 & 0.01018 \\
& $>4.0 \mathrm{ppm}$ & 0.83333 & 0.01018 \\
& $>5.0 \mathrm{ppm}$ & 0.78571 & 0.02082 \\
& $>7.0 \mathrm{ppm}$ & 0.66667 & 0.07099 \\
& $>10.0 \mathrm{ppm}$ & 0.54762 & 0.07099 & 0.16002 \\
\hline
\end{tabular}

Since the above analysis results showed that the density of the surface defects with the absorption over $2 \mathrm{ppm}$ had a tight correlation with the damage performance of the fused silica samples, we thus determined the quantitative relationship between the two variables by nonlinear fitting, as shown in Figure 7 . The $\mathrm{X}$-axis represents the defect density with absorption over $2 \mathrm{ppm}$. The Y-axis represents the zero-probability damage threshold of the samples. Note that there was an exponential decay relationship between the zeroprobability damage threshold and the defect density. The fitting coefficient $\left(R^{2}\right)$ between the two variables was higher than 0.99 , indicating the fitting result is reliable. For the defect density ranging from $0 \mathrm{~mm}^{-2}$ to $95 \mathrm{~mm}^{-2}$, the damage threshold decreased sharply to an almost constant value with the increase in defect density. This clearly showed that the LIDT of the fused silica surface at relatively high fluence (e.g., higher than $6.0 \mathrm{~J} \cdot \mathrm{cm}^{-2}$ ) was more sensitive to the defects at this absorption level. The strict control of these defects might be 
beneficial to significantly improve the laser damage resistance of fused silica optics. There was no obvious change in the zero-probability damage threshold when the density of the defect (>2 ppm) increased from $95 \mathrm{~mm}^{-2}$ to $350 \mathrm{~mm}^{-2}$. It is shown that these high-density absorbing defects had a relatively low damage threshold and could be easily captured by the laser beam spot of the damage testing system.

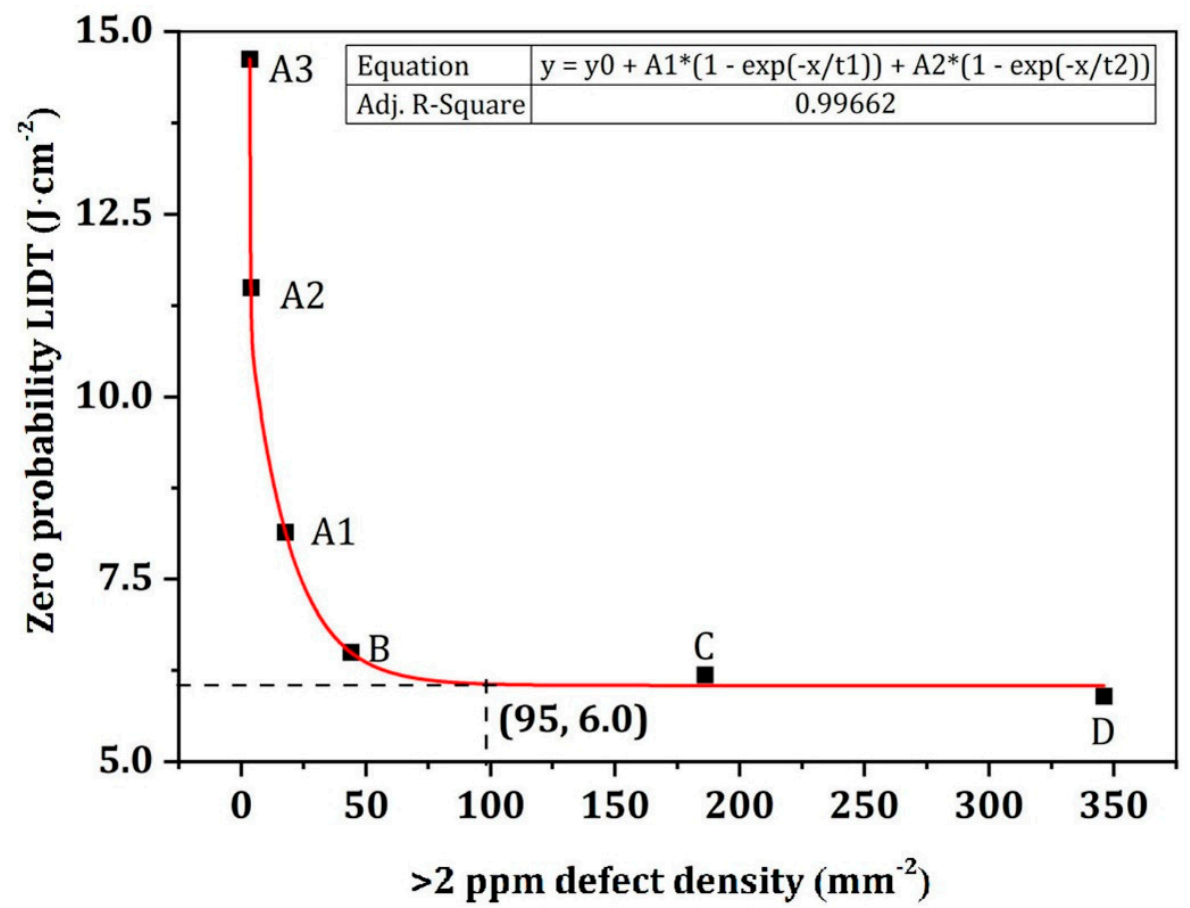

Figure 7. Fitting relationship between defect density with absorption over 2 ppm and zero probability damage thresholds.

A quantitative fitting relationship between the density of the defects (absorption over $2 \mathrm{ppm}$ ) and damage density was obtained, as shown in Figure 8. Note that the damage density increased with the defect density nonlinearly. The fitting coefficient $\left(R^{2}\right)$ between the defect density and damage density was also considerably high, demonstrating that the defect density at this absorption level strongly influenced the damage density of the fused silica samples. When the defect density increased in the range of $5 \mathrm{~mm}^{-2}$ to $300 \mathrm{~mm}^{-2}$, the damage density at $8 \mathrm{~J} \cdot \mathrm{cm}^{-2}$ fluence increased rapidly. At the low defect density range (e.g., lower than $5 \mathrm{~mm}^{-2}$ ), the damage density was relatively low and stable.

The above results and discussions show that the photothermal weak absorption is a feasible method for non-destructively evaluating the damage performance of polished or post-treated fused silica optics by establishing the relationship between the damage performance and defect density with absorption over 2 ppm. Especially for high-density defects at this absorption level, the damage density can be well-predicted. Then in the range of low-density, the density of this kind of defect can reflect the zero-probability damage threshold well. To further determine the distribution characters of the defects with the absorption over 2 ppm on the surface of the samples, we extracted the coordinates and densities of the defects from the obtained weak absorption results, as shown in Figure 9. Many interesting phenomena can be observed from the figure. First, the DCE-treated samples had much lower densities of the defects with the absorption over 2 ppm compared to the polished samples, demonstrating that the DCE post-treatment could effectively remove the defects at this absorption level. It also can be noted that the DCE depth had a weak effect on the density of the defects. Second, for the MRF-treated samples, the densities of the defects with absorption over 2 ppm were greatly different. Especially, the defect density of the sample treated with $5 \mu \mathrm{m}$ MRF was nearly nine times higher than that of the 
sample treated with $1 \mu \mathrm{m}$ MRF. Third, the spatial distribution of the defects on the $5 \mu \mathrm{m}$ MRF-treated sample surface was very uniform. The above results clearly revealed that the distribution characters of the absorbing defects (>2 ppm) which seriously influence the laser damage initiation can be detected non-destructively by using the photothermal absorption technique. It is a very important point for ICF optics because this methodology can be used as a tool to evaluate and optimize the polishing process as well as post-processing of fused silica optical components. For example, for a given low laser operating fluence or damage density, large DCE depth is not necessarily required. It can help us to explore the HF-based shallow etching technique for efficiently removing the dominant defects on the polished fused silica surface.

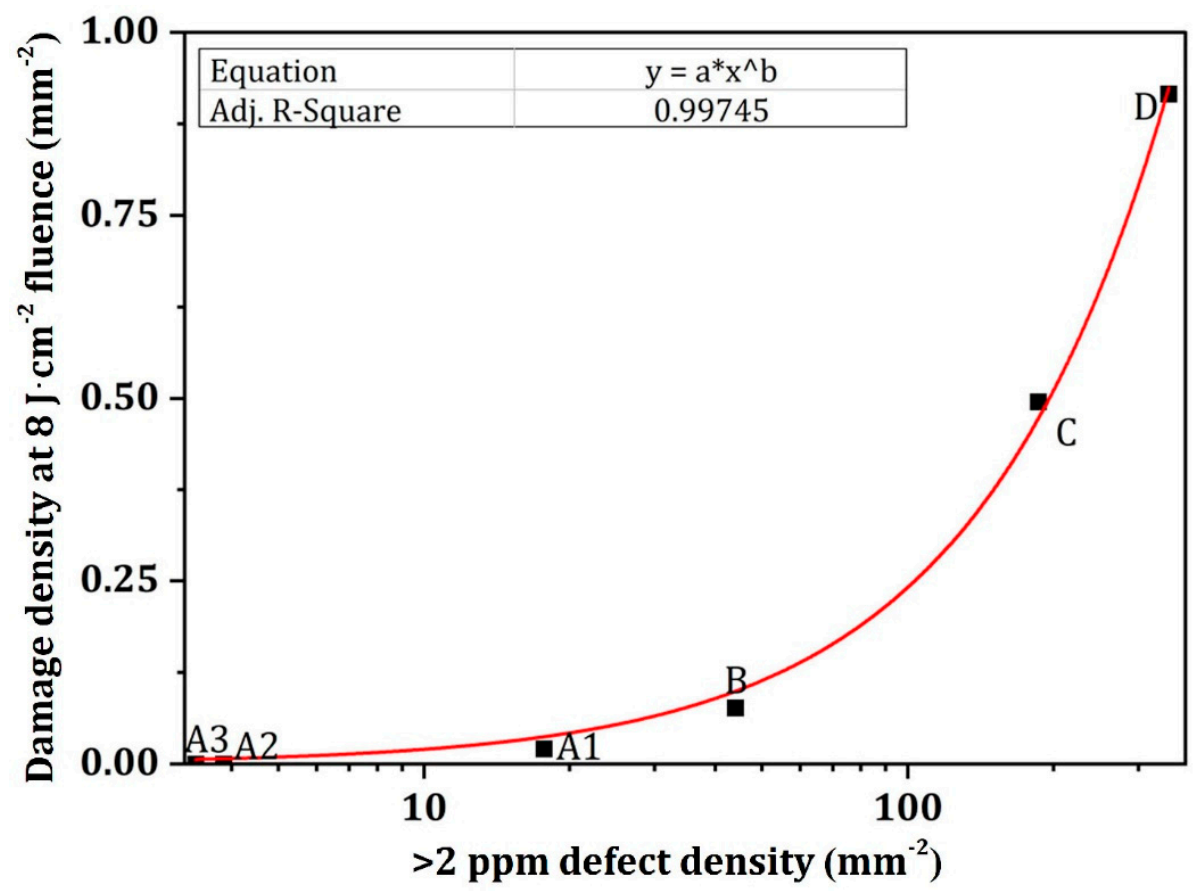

Figure 8. Fitting relationship between defect density with absorption greater than $2 \mathrm{ppm}$ and damage density at $8 \mathrm{~J} \cdot \mathrm{cm}^{-2}$ testing fluence.

(a) A1: original-4.25\%

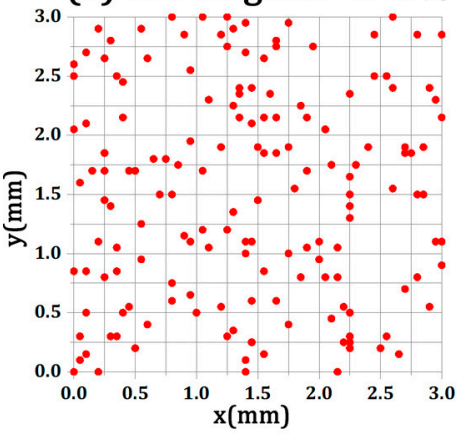

(b) A2: DCE $1 \mu \mathrm{m}-0.89 \%$

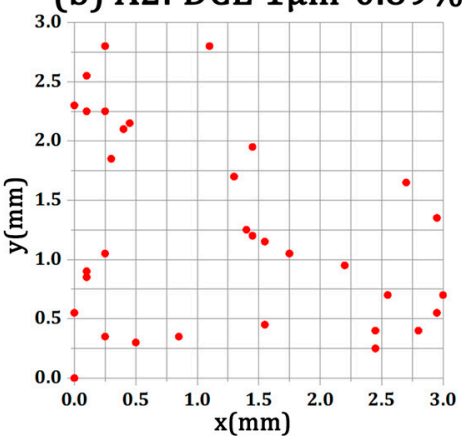

(c) A3: DCE $10 \mu \mathrm{m}-0.64 \%$

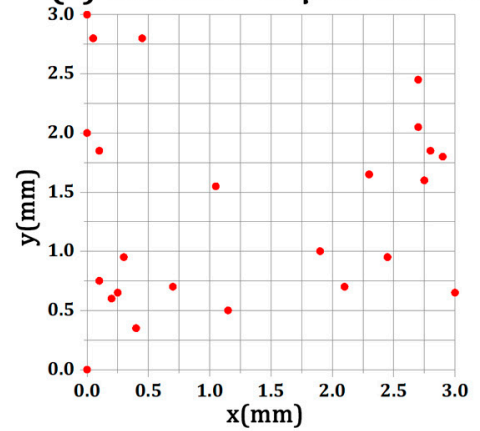

Figure 9. Cont. 
(d) B: MRF $1 \mu \mathrm{m}-6.93 \%$

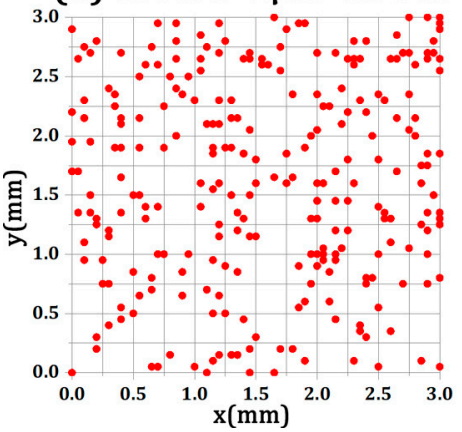

(e) C: MRF $2 \mu \mathrm{m}-40.12 \%$

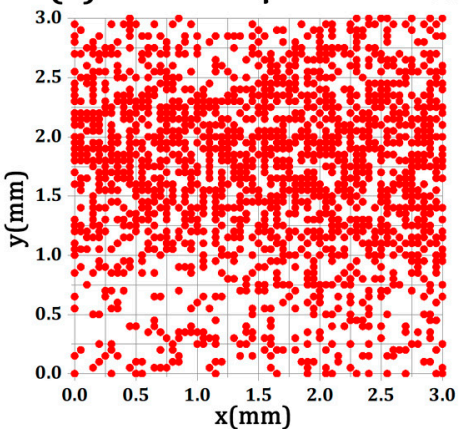

(f) D: MRF $5 \mu \mathrm{m}-60.82 \%$

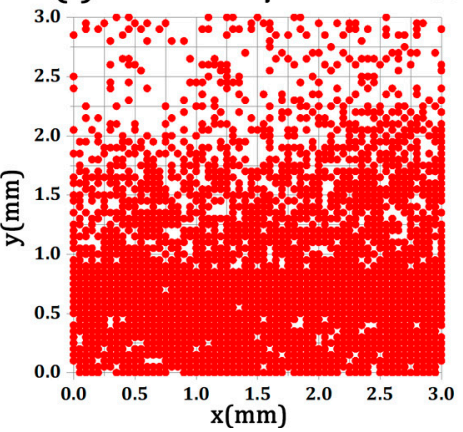

Figure 9. Distribution characters of the defects with the absorption over $2 \mathrm{ppm}$ on the surfaces of the polished and post-treated fused silica samples. The density of the corresponding defects on the surface for each sample is given.

\section{Conclusions}

We studied the distribution characters of surface weak absorption and the $355 \mathrm{~nm}$ nanosecond laser-induced damage performance of fused silica optics post-treated with different processes. The correlation between defects at various absorption levels and damage performance on fused silica surfaces was systematically investigated. The statistical studies show that there are significant correlations between the defect density with absorption over $2 \mathrm{ppm}$ and the damage performance. Results of quantitative fitting illustrate that defect density with absorption over $2 \mathrm{ppm}$ has an exponential decay relationship with damage threshold and a nonlinear growth relationship with damage density. For high-density defects at this absorption level, the damage density of the optics can be well-predicted. In the low-density range, the density of this kind of defect can reflect the zero-probability damage threshold well. This methodology is expected to be applied to non-destructively detect the key absorbing defects on fused silica surfaces, as well as evaluate and optimize the post-treatment level of fused silica optics.

Author Contributions: Conceptualization, Z.S.; methodology, Z.S., F.W. and J.H.; investigation, T.S. and H.L.; writing —original draft preparation, Z.S.; writing-review and editing, L.S. and F.W.; supervision, J.H., X.Y., L.Y. and W.Z.; project administration, L.S. and F.W. All authors have read and agreed to the published version of the manuscript.

Funding: This research was funded by the National Natural Science Foundation of China (62175222, 62005258, and 61805221) and the Laser Fusion Research Center Funds for Young Talents (RCFPD32019-2).

Institutional Review Board Statement: Not applicable.

Informed Consent Statement: Not applicable.

Data Availability Statement: The data that support the findings of this study are available from the corresponding author upon reasonable request.

Acknowledgments: The authors wish to thank eceshi www.eceshi.com (accessed on 7 January 2022) for the weak-absorption analysis.

Conflicts of Interest: The authors declare no conflict of interest.

\section{References}

1. Moses, E.I.; Campbell, J.H.; Stolz, C.J.; Wuest, C.R. The National Ignition Facility: The world's largest optics and laser system. Proc. SPIE 2003, 5001, 1-15.

2. Fleurot, N.; Cavailler, C.; Bourgade, J.L. The Laser Mégajoule (LMJ) Project dedicated to inertial confinement fusion: Development and construction status. Fusion Eng. Des. 2005, 74, 147-154. [CrossRef]

3. Zheng, W.; Zhang, X.; Wei, X.; Jing, F.; Sui, Z.; Zheng, K.; Yuan, X.; Jiang, X.; Su, J.; Zhou, H.; et al. Status of the SG-III solid-state laser facility. J. Phys. Conf. Ser. 2008, 112, 032009. 
4. Menapace, J.; Penetrante, B.; Golini, D.; Slomba, A.; Miller, P.; Parham, T.; Nichols, M.; Peterson, J. Combined advanced finishing and UV-laser conditioning for producing UV-damage-resistant fused-silica optics. Proc. SPIE 2002, 4679, 56-68.

5. Neauport, J.; Lamaignere, L.; Bercegol, H.; Pilon, F.; Birolleau, J.C. Polishing-induced contamination of fused silica optics and laser induced damage density at $351 \mathrm{~nm}$. Opt. Express 2005, 13, 10163-10171. [CrossRef] [PubMed]

6. Bude, J.; Miller, P.; Baxamusa, S.; Shen, N.; Laurence, T.; Steele, W.; Suratwala, T.; Wong, L.; Carr, W.; Cross, D.; et al. High fluence laser damage precursors and their mitigation in fused silica. Opt. Express 2014, 22, 5839-5851. [CrossRef]

7. Miller, P.E.; Suratwala, T.I.; Wong, L.L.; Feit, M.D.; Menapace, J.A.; Davis, P.J.; Steele, R.A. The distribution of subsurface damage in fused silica. Proc. SPIE 2005, 5991, 599101.

8. Suratwala, T.; Wong, L.; Miller, P.; Feit, M.D.; Menapace, J.; Steele, R.; Davis, P.; Walmer, D. Sub-surface mechanical damage distributions during grinding of fused silica. J. Non Cryst. Solids 2006, 352, 5601-5617. [CrossRef]

9. Neauport, J.; Ambard, C.; Cormont, P.; Darbois, N.; Destribats, J.; Luitot, C.; Rondeau, O. Subsurface damage measurement of ground fused silica parts by HF etching techniques. Opt. Express 2009, 17, 20448-20456. [CrossRef]

10. Suratwala, T.I.; Miller, P.E.; Bude, J.D.; Steele, W.A.; Shen, N.; Monticelli, M.V.; Feit, M.D.; Laurence, T.A.; Norton, M.A.; Carr, C.W.; et al. HF-Based Etching Processes for Improving Laser Damage Resistance of Fused Silica Optical Surfaces. J. Am. Ceram. Soc. 2011, 94, 416-428. [CrossRef]

11. Ye, X.; Huang, J.; Liu, H.; Geng, F.; Sun, L.; Jiang, X.; Wu, W.; Qiao, L.; Zu, X.; Zheng, W. Advanced Mitigation Process (AMP) for Improving Laser Damage Threshold of Fused Silica Optics. Sci. Rep. 2016, 6, 31111. [CrossRef] [PubMed]

12. Shi, F.; Tian, Y.; Peng, X.; Dai, Y. Combined technique of elastic magnetorheological finishing and HF etching for high-efficiency improving of the laser-induced damage threshold of fused silica optics. Appl. Opt. 2014, 53, 598-604. [CrossRef] [PubMed]

13. DeMange, P.; Carr, C.W.; Radousky, H.B.; Demos, S.G. System for evaluation of laser-induced damage performance of optical materials for large aperture lasers. Rev. Sci. Instrum. 2004, 75, 3298-3301. [CrossRef]

14. Lamaignère, L.; Balas, M.; Courchinoux, R.; Donval, T.; Poncetta, J.C.; Reyné, S.; Bertussi, B.; Bercegol, H. Parametric study of laser-induced surface damage density measurements: Toward reproducibility. J. Appl. Phys. 2010, 107, 023105. [CrossRef]

15. Demos, S.G.; Negres, R.A. Time-resolved imaging of material response during laser-induced bulk damage in $\mathrm{SiO}_{2}$. Proc. SPIE 2008, 7132, 71320Q.

16. Bercegol, H.; Grua, P. Fracture related initiation and growth of surface laser damage in fused silica. Proc. SPIE 2008, 7132, 71321B.

17. Fieberg, S.; Waasem, N.; Kühnemann, F.; Buse, K. Sensitive absorption measurements in bulk material and coatings using a photothermal and a photoacoustic spectrometer. Proc. SPIE 2014, 8964, 896410.

18. Alexandrovski, A.; Fejer, M.; Markosian, A.; Route, R. Photothermal common-path interferometry (PCI): New developments. Proc. SPIE 2009, 7193, 71930D.

19. ISO 11551:2003; Optics and Optical Instruments-Lasers and Laser-Related Equipment-Test Method for Absorptance of Optical Laser Components. International Standard. International Organization for Standardization: Geneva, Switzerland, 2003.

20. Waasem, N.; Fieberg, S.; Hauser, J.; Gomes, G.; Haertle, D.; Kuhnemann, F.; Buse, K. Photoacoustic absorption spectrometer for highly transparent dielectrics with parts-per-million sensitivity. Rev. Sci. Instrum. 2013, 84, 023109. [CrossRef]

21. Leidinger, M.; Fieberg, S.; Waasem, N.; Kuhnemann, F.; Buse, K.; Breunig, I. Comparative study on three highly sensitive absorption measurement techniques characterizing lithium niobate over its entire transparent spectral range. Opt. Express 2015, 23, 21690-21705. [CrossRef]

22. Huang, J.; Wang, F.; Liu, H.; Geng, F.; Jiang, X.; Sun, L.; Ye, X.; Li, Q.; Wu, W.; Zheng, W.; et al. Non-destructive evaluation of UV pulse laser-induced damage performance of fused silica optics. Sci. Rep. 2017, 7, 16239. [CrossRef]

23. Liu, H.; Wang, F.; Huang, J.; Meng, J.; Ma, Y.; Lian, Y.; Sun, L.; Ye, X.; Geng, F.; Jiang, X.; et al. Experimental study of 355 nm laser damage ignited by Fe and Ce impurities on fused silica surface. Opt. Mater. 2019, 95, 109231.

24. Yan, C.; Liu, B.; Li, X.; Liu, C.; Ju, X. Photothermal spectroscopy study of fused silica irradiated by a $355 \mathrm{~nm}$ wavelength and $68 \mathrm{~ns}$ pulse duration laser. Opt. Mater. Express 2019, 9, 3439-3451. [CrossRef]

25. Zhong, Y.; Dai, Y.; Shi, F.; Song, C.; Tian, Y.; Lin, Z.; Zhang, W.; Shen, Y. Effects of Ion Beam Etching on the Nanoscale Damage Precursor Evolution of Fused Silica. Materials 2020, 13, 1294. [CrossRef]

26. Xu, M.; Shi, F.; Zhou, L.; Dai, Y.; Peng, X.; Liao, W. Investigation of laser-induced damage threshold improvement mechanism during ion beam sputtering of fused silica. Opt. Express 2017, 25, 29260-29271. [CrossRef]

27. Sun, L.; Huang, J.; Shao, T.; Ye, X.; Li, Q.; Jiang, X.; Wu, W.; Yang, L.; Zheng, W. Effects of combined process of reactive ion etching and dynamic chemical etching on UV laser damage resistance and surface quality of fused silica optics. Opt. Express 2018, 26, 18006-18018. [CrossRef]

28. Stuart, B.C.; Feit, M.D.; Herman, S.; Rubenchik, A.M.; Shore, B.W.; Perry, M.D. Nanosecond-to-femtosecond laser-induced breakdown in dielectrics. Phys. Rev. B 1996, 53, 1749-1761. [CrossRef]

29. Liu, H.; Huang, J.; Wang, F.; Zhou, X.; Ye, X.; Zhou, X.; Sun, L.; Jiang, X.; Sui, Z.; Zheng, W. Subsurface defects of fused silica optics and laser induced damage at $351 \mathrm{~nm}$. Opt. Express 2013, 21, 12204-12217. 